\title{
DATOS BIOGRÁFICOS DEL DR. LUIS E. VALCÁRCEL
}

$\mathrm{N}$ ació en Ilo (Moquegua) el 8 de febrero de 1891. Cursó estudios primarios y secundarios en el Cuzco, en cuya Universidad se graduó de Doctor en Filosofía, Letras, Historia y Derecho y concluyó estudios en Ciencias Económicas. Ingresó a la docencia en 1911 en el Colegio Nacional de Ciencias de aquella ciudad y en 1917 en su Universidad, como catedrático de Historia del Perú e Historia del Perú Antiguo en la Facultad de Letras de la Universidad Nacional Mayor de San Marcos, en donde enseñó, además, desde 1946, Historia del a Cultura Peruana e Introducción a la Etnología.

En 1930 fue nombrado Director del Museo Bolivariano y luego Director del Museo de Arqueología Peruana. En 1931 fue nombrado Director del Museo Nacional, que comprendía todos los museos del Estado, ejerciendo este cargo hasta 1945, en que pasó a dirigir el de Historia.

Ha sido fundador de las siguientes instituciones: Museo Arqueológico de Lima, 1934; Instituto de Arte Peruano, 1931; Instituto de Investigaciones Antropológicas, 1931. En 1946, siendo Ministro de Educación Pública, estableció el Museo de la Cultura Peruana y el Instituto de Estudios Etnológicos, el Conservatorio Nacional de Música, la Escuela Regional de Bellas Artes del Cuzco, el Museo Histórico de Ayacucho, las Escuelas Regionales de Música de Trujillo y Arequipa, el Museo Virreinal del Cuzco, el Instituto Politécnico Nacional y los Institutos Politécnicos Regionales, los Núcleos Escolares Campesinos y muchos otros centros de educación y cultura. Ha ejercido su profesión de abogado hasta 1930.

En Mayo de 1955 fue elegido, por unanimidad, Decano de la Facultad de Letras de la Universidad Nacional Mayor de San Marcos. Desde muy joven ejerció el periodismo, habiendo dirigido y siendo redactor de los periódicos cuzqueños El Comercio, El Sol, El Sur, El Cuzco, La Revista, La Sierra, Revista Universitaria. Es antiguo colaborador de La Prensa de Buenos Aires y de crecido número de revistas del Perú y del extranjero. Publicaciones: más de 30 libros y opúsculos, siendo los principales: Del Ayllu al Imperio, De la Vida Incaica, Tempestad de los Andes, Mirador Indio, Cuentos y Leyendas Incas, Garcilaso el Inca, El Virrey Toledo, gran tirano del Perú, Historia de la Cultura Antigua del Perú (2 tomos). En preparación: los dos tomos restantes de la última obra mencionada y el tomo primero de la Historia General del Perú, en colaboración. Director de la Revista del Museo Nacional.

Pertenece a las instituciones siguientes: Instituto Histórico, Sociedad Geográfica, Academia Nacional del Ciencias, Asociación Nacional de Escritores y Artistas (de que ha sido Presidente), Instituto Cultural Peruano-Norteamericano (del cual fue miembro fundador y Presidente), 
Societé des Americanistes de Paris, Sociedad de Historia de Geografía de Chile. Ha asistido a numerosos congresos y conferencias internacionales y el 1947 fue Presidente de la Delegación Peruana a la reunión de la UNESCO en México, 1941 fue invitado por el Departamento de Estado para hacer un recorrido por los Estados Unidos, en 1949 lo que del Consejo Británico. Ese mismo año fue especialmente invitado por la UNESCO para participar en dos reuniones de expertos en artes de monumentos. Es miembro del Comité Internacional de Monumentos Históricos y Artísticos y de la redacción de la revista Museum de París. Fue vicepresidente ejecutivo de la Junta de Reconstrucción y Fomento Industrial del Cuzco. Como Director del Instituto Etnográfico de la Universidad San Marcos ha realizado el estudio de cerca de 30 pueblos del Perú. Fue el primer Director del Instituto Indigenista Peruano y fundador de su revista Perú Indígena. A pedido de la UNESCO presentó, en 1911, un estudio sobre la enseñanza del campesino en su idioma materno. Fundó la Escuela de Arte Escénico, la Escuela de Escenografía, la Compañía Nacional de Teatro y las Secciones de Teatro y Folklore en la Dirección de Educación Artística y Extensión Cultural. Tomó parte en los Congresos Nacionales de Peruanistas en 1951 y de Historia de la Independencia en 1954 y el Symposium sobre el Inca Garcilaso en 1955. Ha sido condecorado por diversos gobiernos de América y Europa.

Datos tomados de la obra Peruanos de Hoy, la edición de 1957 